\title{
Assessment of Relationship between Young Researchers and Mentors and Implications for Knowledge Transfer
}

\author{
ANA ARZENŠEK \\ University of Primorska, Slovenia \\ ana.arzensek@fm-kp.si \\ KATARINA KOŠMRLJ \\ University of Primorska, Slovenia \\ katarina.kosmrlj@fm-kp.si
}

Key factors in relationships among Slovenian postgraduate students with a Young researcher status and their mentors are addressed. It was assumed that relationship determines assessment of the usefulness of the training and of knowledge transfer by Young researchers. The problem was explored quantitatively with a survey and qualitatively with focus groups method. Results show that Young researchers are on average satisfied with their mentors and were given good guidance both in contents and methodology. Differences can be observed regarding inclusion in research projects, where mentors of Young researchers in economy scored lower. With factor analysis it was shown that factor 'mentorship' is significantly correlated with the assessment of the programme. Analysis of focus groups indicated diverse experiences in mentoring both groups reported about. It was concluded that mentors who encourage the transfer of knowledge are exceptional in their ability to communicate and are teamwork-oriented; they foster active involvement of the candidate in the research group.

Key words: higher education, knowledge transfer, mentors, relationship, young researchers

https://doi.org/10.26493/1854-4231.12.273-292

\section{Introduction}

In this section mentoring in postgraduate education in Slovenia is presented. More specifically, descriptions of the Young researcher (YR) programme and mentoring in the YR programme are provided together with research aims and research questions.

MENTORING IN POSTGRADUATE EDUCATION

Anderson and Shannon $(1988,40)$ define mentoring as 'a nurturing process in which a more skilled or experienced person, serving as a 
role model, teaches, sponsors, encourages, counsels and befriends a less skilled or less experienced person for the purpose of promoting the latter's professional and/or personal development.' According to the definition, mentor's role extends beyond giving advice to the students regarding their theses to his role in building professional and personal skills.

Besides providing both explicit and tacit knowledge about their fields and giving clear and timely feedback (Paré 2011), mentors may encourage students to finish their programmes and stay in the field. Constructive relationships between mentors and doctoral students have been implicated in positive outcomes for the students (Curtin, Malley, and Stewart 2014; Paglis, Stephen, and Bauer 2006). Research indicates that the mentor-doctoral student interpersonal relationship is associated with good progress of the work and its completion (Devos et al. 2015), and with positive psychosocial outcomes, such as student satisfaction, sense of competence (Mainhard et al. 2009), identification with the field, confidence about being able to make a contribution (Curtin, Malley, and Stewart 2014) and with production of more publications (Titus and Ballou 2014).

Denicolo (2004) reports on positive characteristics of mentors as seen by doctoral students. Predominantly reported characteristics of mentors are reliability, confidence in the student, encouragement, broad-mindedness and openness to share knowledge. Among soft skills are good listening skills, open communication that allows debate and argumentation, providing continuous feedback and support, enthusiasm as well as personal warmth and understanding. Seagram, Gould, and Pyke (1998) showed that important positive attributes of high quality mentors as perceived by doctoral students were mentor's professionalism, being pleasing and expressing supportive behaviour.

\section{YR(E) TRAINING PROGRAMME}

In Slovenia, the YR training programme has been developed in order to promote scientific development, to reduce the age profile of research groups and to strengthen links to knowledge transfer into practice. The programme is based on doctoral students (YRS), who participate in research work during their postgraduate studies on basic research or applied research projects. Candidates for the training have to apply to the mentors and are chosen by the mentor. Among YR candidates those with best academic profile and personal characteristics fitting to the YR work position are selected. Mentors to YRS have to meet various academic criteria and have to be suc-

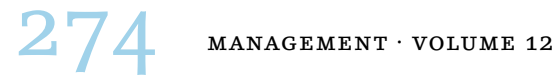


cessful in the Call for mentors for YRs within Slovenian Research Agency (2017). Criteria for candidates' successful application are academic excellence and promising research plan (Arzenšek, Košm$\mathrm{rlj}$, and Širca 2014). More than 6.000 Y RS have participated in the programme. Since then the YR training programme has become an important scientific policy instrument. Since its' implementation in 1985, Slovenian Research Agency dedicates a significant amount of its budget to finance the training. On average, 30,000.00 EUR are provided annually per YR. The programme is financed up to three and a half years according to Bologna scheme in doctoral education.

In spite of its success in promotion of doctoral studies, the gap between university, industry, and governments remained broad. In order to achieve faster transition of discoveries from university to the end-users (in the form of patents, licences, good practices, joint ventures and spin-off companies), the Slovenian government additionally developed a Young researchers in economy (YRE) training programme (Arzenšek, Košmrlj, and Širca 2014). The YRE training programme aims at strengthening research and development ability as well as improving links and knowledge transfer between the academic, research and economic spheres. Since 2007, more than 240 YRES have been included in the programme (Slovenian Research Agency 2017). As a consequence, faster knowledge transfer from universities to industry and vice versa was possible.

While YRS are normally employed in a higher education institution/ research institute and they normally do a research study under the mentorship of one or two faculty members, YRES have one mentor from university and another one from the company they are employed in. The programme for YRES includes a second mentor, called mentor in company. Their main task is to support the YRE'S research according to the needs of the employing company. Mentors in company are usually not academics, but practitioners, though they are often highly educated and are experienced in the economic sector. Both kinds of mentors not only support and guide YR(E)S, but also play an important role in the assessment of the quality of the final manuscript submitted (Mainhard et al. 2009).

MENTORING IN YR(E) TRAINING PROGRAMME

The Slovenian Doctoral Students and Young Researchers' Association (YDRA, see http://www.mladaekonomija.si) has been collecting YR'S and other doctoral students' experience and comments about mentoring practices and modes of conduct in training of YRS in different institutions. In spite of many negative cases of mentoring that 
were reported by their members, their aim is to provide positive practices of mentoring experience. According to YDRA, an ideal mentor of a doctoral student 'shows correct regard for the mentee, is accessible, and prepared to invest enough time for the YR or doctoral student. A mentor includes mentees into his research team work and allows them to make contacts and ingrates them into the international research community. A mentor is a specialist in the field of operation of YRS or at least he enables professional work on the highest level through collaboration with other researchers on national or international level.' (see http://www.mladaakademija.si/mentor-leta/). According to YDRA, a mentor also strives to transfer as much knowledge and experience as possible in order to stimulate the future career of YR.

\section{RESEARCH AIMS}

In spite of much overlap in the literature regarding mentor's characteristics and importance of interpersonal relationships in the progress of preparing a doctoral dissertation, little is known about the expectations of $\mathrm{YR}(\mathrm{E}) \mathrm{S}$, especially as $\mathrm{YR}(\mathrm{E}) \mathrm{S}$ are many times among the most talented doctoral students and might have specific expectations and needs in comparison to other doctoral students. Especially the role of YRES is a complex and demanding one as they have to go through doctoral education and at the same time they have to spend certain amount of time working on the research project in the company. So it was important for us to explore needs and experiences of $\mathrm{YR}(\mathrm{E}) \mathrm{S}$ in their relationship with their mentor(s), as it can bring some implications for higher education policies. Furthermore, mentors of YR $(\mathrm{E}) \mathrm{s}$ might also have different expectations and modes of operation in comparison to other doctoral students' mentors. It is important to explore the perspectives of both relational parties in order to enhance our understanding. The mentor's role in the YR $(\mathrm{E})$ 'S progression is thus a complex one and needs further investigation.

The predominant aim in the present study was to search for specific experience and relationships between mentors of YRS and YRES in the YR(E) programmes. As there are two kinds of YRS included in the YR programme, namely YRS and YRES, both groups took part in the research. On this basis, two hypotheses were developed:

$\mathrm{H} 1$ The relationship with the mentor is important for the assessment of the usefulness of the $\mathrm{YR}(\mathrm{E})$ training.

$\mathrm{H} 2$ The relationship with the mentor is important for $\mathrm{YR}(\mathrm{E})$ knowledge transfer.

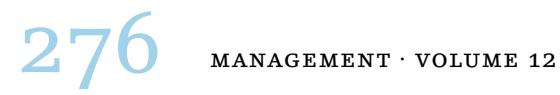


As categories under observation (relationship with the mentor/ mentee, usefulness of $\mathrm{YR}(\mathrm{E})$ training, knowledge transfer) can be perceived in several different ways by participants and because the survey did not allow space for exploration of personal characteristics of both mentors and YR (E)S, we additionally organised focus groups in order to clarify different experiences of mentor-mentee dynamics within YR $(\mathrm{E})$ training programme. Four research questions were developed to investigate within 3 separate focus groups:

1. What is important for participants in their relationship with YR (E) S/mentor(s)?

2. What was their own relationship with their YR(E) S/mentor(s)?

3. What obstacles did they experience in their relationship with YR (E) S/mentor(s) (if any)?

4. Do they have any suggestions for relationship improvement?

\section{Methods}

In this section structure of the sample is presented. Furthermore, descriptions of the instruments and procedures are provided.

\section{SAMPLE \\ Survey Sample}

The population consisted of all YRS and YRES who have either already finished the training or are still included in the programme. Altogether, 3763 e-mail addresses were contacted. Of these, 404 were inexistent (invalid) and another 20 were unavailable (either on holiday, business trip, maternity leave or on medical leave). From the addresses reached, 695 viewed the questionnaire and 478 complete questionnaires were returned $(14.2 \%$ response rate). The sample was consisted of $77 \%$ of YRS and $23 \%$ YRES. Only 3 (0.6\%) people that completed the questionnaire interrupted the training, 58\% completed the training successfully and $41 \%$ were still included in the YR programme at the time of the interview. Less than $7 \%$ of the sample was included in masters study programmes, and the majority of $93 \%$ in doctoral study programmes. The majority of the sample $(73 \%)$ studied in natural or technical sciences, about a fifth (21\%) in social sciences and humanities, and $6 \%$ in medicine, healthcare, social services and other services.

\section{Focus Groups Sample}

Three separate focus groups were carried out with altogether 17 participants. The composition of each focus group was homogeneous in 
TABLE 1 Characteristics of Participants in Focus Groups

\begin{tabular}{llr}
\hline Characteristic & & Number \\
\hline Role in the programme & YR & 7 \\
& YRE & 4 \\
& Mentor & 6 \\
\hline Training status* & In progress & 8 \\
& Finished & 9 \\
\hline Training discipline** & Social sciences & 7 \\
& Natural sciences & 4 \\
& Engineering & 6 \\
\hline Occupational status & Higher education institution & 5 \\
& Public research institute & 4 \\
& Economy & 7 \\
\hline
\end{tabular}

NOTES *For mentors status of their YR(E) mentees. ** Training disciplines were merged according to Frascati classification (natural sciences and medicine to natural sciences; engineering, technical sciences and agriculture to engineering; social sciences and humanities to social sciences). $n=17$.

terms of participant status (separately for YRS, YRES and mentors of YRS and YRES). At the same time, the composition was as heterogeneous as possible in terms of variety of participants' scientific disciplines and place of residence (in Slovenia, this is often linked to institution they are employed/study at). Table 1 shows the composition of focus groups. Additional criterion was having at least two years of experience with the YR programme (for YRS and YRES) and at least one already finished mentorship in YR programme (for mentors).

Each participant was given a short survey with demographic data and with questions regarding their experience with YR training.

\section{INSTRUMENTS}

The research problem was dealt quantitatively with survey and qualitatively with focus group method. With the latter we wanted to clear up some aspects of the problem that had not been resolved in the survey or the answers had been only partial.

\section{Survey}

The questionnaire was comprised of 30 questions: 10 for independent and 20 for dependent variables. The variables were deducted from analysis of key concepts to the research subject. The concepts were defined through theory and previous research analysis. Each

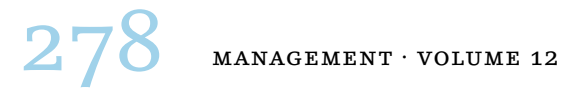


question for dependent variables was composed of a few items statements to assess agreement, satisfaction or validity on a 6-grade Likert-type scale. The questionnaire was pilot-tested on a purposive sample of 15 relevant individuals from the researchers' social network. Some of the questions were modified based on comments from the testing.

\section{Focus Groups}

Focus groups are a research technique for data gathering through group interaction. The main theme is provided by researchers. Their research interest provides a focus for group discussion. Group interaction provides opportunities for tacit views gathering, as they are being manifested through group dynamics (Morgan 1997, 6). According to Morgan (1997) focus groups require fewer resources in comparison to individual interviews (time, money).

This type of research does not allow generalisation of its results to other populations and time frames. Furthermore, prediction of trends is limited as well (Churchill and Iacobucci 2005, 77; Edmunds 1999, 2). It allows, however, in-depth insights into habits, thinking modes and rationale for behaviour of groups under research.

\section{PROCEDURES}

\section{Survey}

The survey was held on-line (LimeSurvey). An invitation with a brief presentation of the research, the scope of the survey and the link to the questionnaire was sent to email addresses given by the Slovenian Research Agency and the Slovenian Agency for Technological Development (now SPIRIT Slovenia). The call was repeated after three weeks in order to achieve a satisfactory number of respondents. Data was checked after the closing of the survey and incomplete units were omitted from the analyses. Data was analysed using spss software.

In the first phase, variables were analysed using descriptive statistic methods, groups values were compared using independent $t$-test (significance threshold 5\%). Factor analysis was used to assess the validity of the questionnaire, as well as to determine the variables to compute new variables depicting dimensions for testing the hypotheses. The hypotheses were tested with linear regression.

\section{Focus Groups}

Two researchers were involved in focus groups implementation. One of them was in charge of leading the focus groups and the other 
transcribed the contents verbatim. According to Patton (2002), a focus group protocol was designed in order to assure higher reliability. A list of themes to be addressed in focus groups accompanied the progress (e.g. mentor-YRE relationship attributes, obstacles in the relationship between $\mathrm{YR}(\mathrm{E})$ and mentor, etc.). At the beginning, the interviewer started with a short introduction to the study and with its ethical considerations. Participants were asked to introduce themselves and to provide a short explanation of reasons for being included into YR $(\mathrm{E})$ programme. Open-ended questions were posed (e.g. 'What are the most important attributes of mentors?') and participants explained their views through an open discussion. Sub questions were posed in order to guarantee balanced contributions of all participants and to ensure ambiguities were cleared up.

\section{Results}

Analysis of answers in the survey showed that a mentor has influence on YR training evaluation and on YRs' motivation for knowledge transfer. Focus groups additionally confirmed that mentors' role was one of key characteristics in the training of $\mathrm{YR}(\mathrm{E}) \mathrm{S}$. Herewith, detailed results of quantitative as well as of qualitative part of research are provided.

SURVEY RESULTS

This section presents the results of the analyses of survey data concerning YR(E)-mentor relationship and the influence of this relationship on knowledge transfer. Two questions were dedicated to the relationship topic: the first included items about different aspects of the relation with the mentor in the academic institution and the other about relation with the mentor in economy (i.e. mentor in the employing company). To test the first hypothesis, items regarding assessment of the training were analysed. To test the second hypothesis, the number of projects (scientific, research or with end-users) was considered as an indicator of knowledge transfer.

\section{Relationship with the Mentor}

Table 2 shows respondents' opinion on different aspects of cooperation with the mentor in the academic institution. All mean values are above median value, so overall assessment is fairly good. Both groups, YRS and YRES assess cooperation with the mentor as very good with mean value around 5 on the 6 -grade scale (1 denotes total disagreement, 6 denotes total agreement). Mentors were, on average, accessible to YRS and YRES and provided satisfactory support in

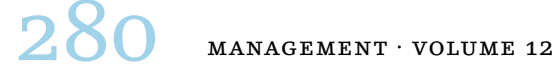


both contents and methodology. Mentors were also accessible and promptly responsive.

Respondents were somewhat undecided about the mentor giving them more attention than non YR(E) doctoral students. This shows mentor's neutral position (on average), which is good in terms of equality, but on the other hand one of the YR(E) programme's purposes is for the trainees to get more attention from their mentor in order to become more (academically) competent. On the other hand, YRS report that mentors expect more from them in comparison to other $\mathrm{PhD}$ students.

Some differences between the YRS and YRES can be observed also regarding inclusion in projects - either scientific research projects or projects with economy. On average, YRS report higher agreement about their mentor's actively including them into research projects than YRES (table 2). This can be explained with the nature and environment of the training of YRS and YRES. While the latter usually work in a company on a specific project to be reported in their thesis, the first tend to be included in their mentors' research groups and as such work on more than one project along with the research for their thesis.

As table 3 shows, YRES were on average satisfied with the cooperation with the company mentor, however, mean values are a bit lower than with the items regarding the cooperation with the academic mentor. An almost complete agreement can be observed regarding equal treatment of the YRE compared to other employees. As opposed to the academic mentors, company mentors got a better score regarding inclusion in projects. Both results can be argued as comprehensive inclusion of the YRE in the working team in the employing company, which subsequently leads to knowledge transfer. There are no differences in the overall assessment of the mentor between different fields of study.

\section{Relationship with the Mentor's Influence on Training Usefulness}

The variables measuring the relationship with the mentor were included in factor analysis regarding the assessment of the programme. In total, 33 items from the questionnaire were included in the model with good overall reliability (Cronbach $\alpha$ o.86 on standardized values), and high кмо (0.82) proves the data are fit for analysis. The model with 5 factors accounts for $47.5 \%$ of variance, while the factor of academic mentor-YR(E) relationship explains $16.4 \%$ of variance in the assessment of the training (Cronbach $\alpha 0.92$ on standardized values). Variables influenced with the factor were used 
Ana Arzenšek and Katarina Košmrlj

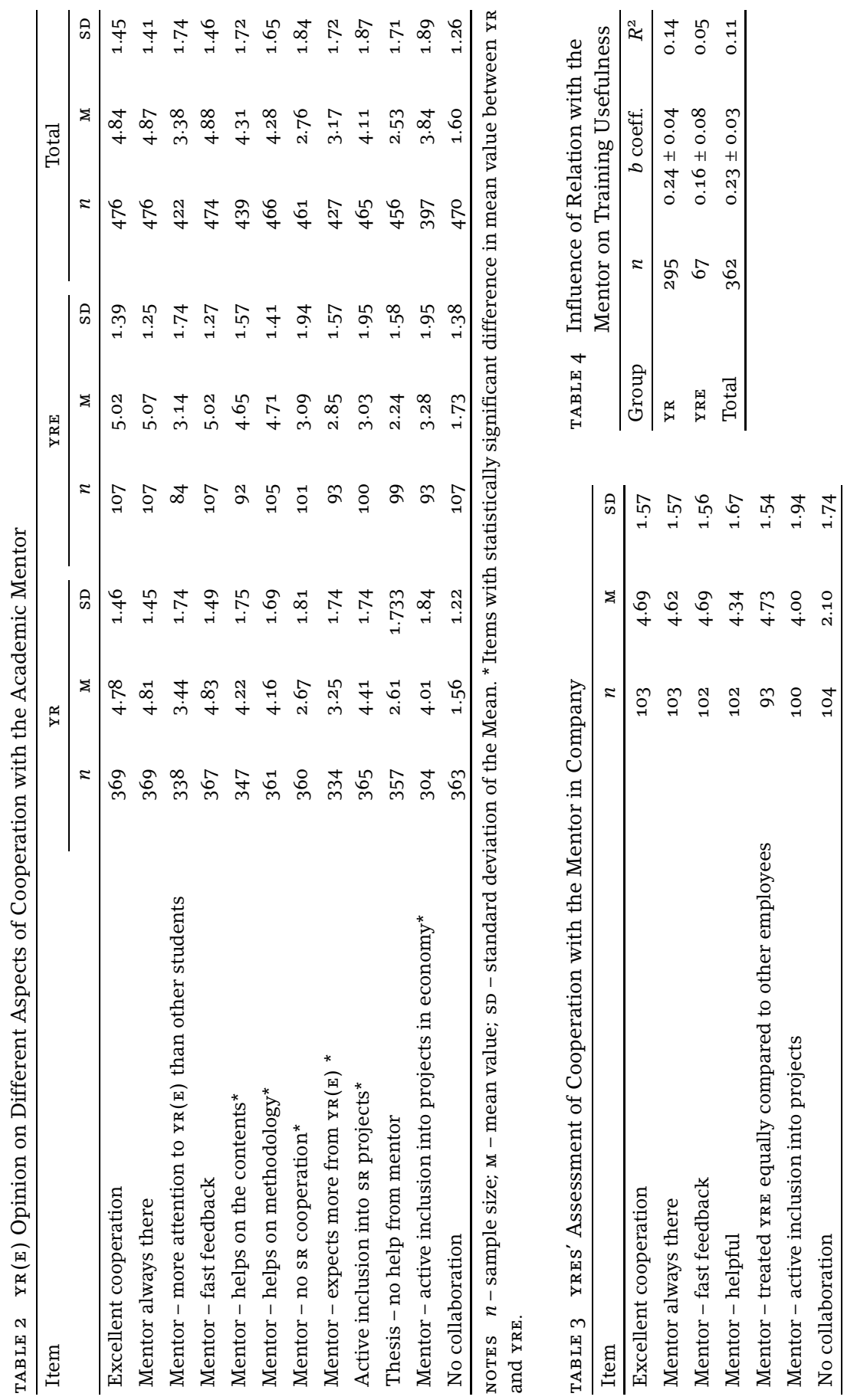


to compute a new variable, average score of relationship with the mentor (MENTOR). The assessment of the training's usefulness was computed as average score of three variables, based on component analysis of variables regarding different aspects of knowledge transfer explaining a total of $57.5 \%$ of the variance. The overall reliability of the model was sufficient (Cronbach $\alpha 0.74$ on standardized values) and data were fit for analysis based on кмо 0.74. This component explains $14.9 \%$ of variance in knowledge transfer (Cronbach $\alpha 0.72$ on standardized values).

By using linear regression analysis, we tested the influence of the relationship with the mentor on the assessment of the usefulness of the training. The base model was posed as:

'training_usefulness' $=\mathrm{a}+\mathrm{b} \cdot$ 'mentor' + e.

Results show that the influence is statistically significant; the model is valid with $p<0.01$. The relationship with the mentor has a higher impact in the YR group as demonstrated in table 4. For each additional grade of mentor relationship assessment, a 0.24 higher grade in training usefulness of YRS is expected on average (on the 6 -grade scale), not including other influencing factors. The model includes only assessment of the relationship with the academic mentor, which can explain the lower impact in the YRE group, where each additional grade in mentor relationship is expected to increase the training usefulness of YRES for 0.16 grades on average (on the 6-grade scale), not including other influencing factors.

Based on these results, the first hypothesis can be confirmed. The impact is statistically significant and accounts, in total, for about a quarter of a grade. However, it needs to be pointed out that the regression model explains only a small part of variance in training usefulness assessment, $14 \%$ in the YR group and $5 \%$ in the YRE group. This means that other factors influence the usefulness of the training, among which some are random, and some can be denoted from the theory: employment at the time of surveying, specialization in the study field, fulfilling of expectations, intrinsic motivation and other.

\section{Relationship with the Mentor's Influence on Knowledge Transfer}

The influence of the relationship with the mentor on knowledge transfer was tested in a similar way as the influence on usefulness of the programme. Since knowledge transfer was directly measured with number of projects completed or in progress, we computed a 
bivariate linear regression model at first. This did not prove the second hypothesis suggesting that the relationship with the mentor is important for YR(E) knowledge transfer, for the model was not statistically significant.

The number of projects variable has a very asymmetrical distribution, with a significant right skew (with values ranging from 1 to 88). Thus we computed a new categorical variable with value o denoting no activity in projects and value 1 denoting activity in at least one project. With this new variable, we computed a logistic regression model. The result was better, but the model still did not prove to be significant at a low enough $p$-value.

Thus, we have to conclude that our second hypothesis cannot be confirmed by using data from survey. One of the reasons for such a result is in the measurement of knowledge transfer, which should have been more elaborated. On the other hand, academic mentors' task is to support the YRS and YRES in preparation of their doctoral thesis and the knowledge transfer aspect is only an additional benefit. However, it should be considered to activate and empower the academic mentors on the knowledge transfer aspect of training in order for the programme to become more efficient.

\section{FOCUS GROUPS RESULTS}

\section{Mentors' Role in the Training}

In spite of the fact that $P$ hD candidate was considered as free in terms of thesis definition and preparation, participants concluded mentoring process was one of key characteristics in successful completion of a thesis. Participants also emphasised role of personality in the process of thesis preparation and completion. Diverse experience regarding mentor-YR $(\mathrm{E})$ relationship was described and it was meaningfully divided into three homogeneous categories, namely: (1) favourable mentor characteristics, (2) mentor-YR (E) relationship and (3) obstacles in mentor-YR (E) relationship. Detailed descriptions of each category with examples of quotes are provided, where abbreviations YR, YRE and MNT (mentors) stand for each of three focus groups and letters $A-G$ denote individual participants within each focus group.

\section{Favourable Mentor Characteristics}

A list of desirable mentor characteristics was, interestingly, diverse. Different groups provided different views on what were considered important characteristics of mentors, probably because of different 
motivations for entering the programme and different positions in $\mathrm{YR}(\mathrm{E})$ training.

To sum up, key mentor characteristics that lead to effective YR training were: understanding, accessible, providing support and capable to motivate, as well as having broad knowledge and broadmindedness, integrity (being aware of one's boundaries and respect of intellectual property), good organisation skills.

That he doesn't force his ideas, doesn't force you, so that you come to results by yourself. [YRE_B]

To know his limits [...] when he doesn't know something [...] while being a YR, you are not his clone [...] to realise his boundaries. 'I don't know this' stance. To pick up the phone and asks others. That he doesn't consider himself as god only by being a mentor. That he's fair and doesn't steal results. [YR_G]

I have a good experience, he had everything well organised. He had everything elaborated. [YR_E]

Best mentors are those with social touch. Maybe they're not best researchers [...]. [YR_D]

\section{Mentor-yR(Е) Relationship}

Relationship dimension was very much exposed during focus groups. In spite of difficulties to differentiate this category from (personal) characteristics of both mentor and $\mathrm{YR}(\mathrm{E})$, this category was constructed in order to show importance of mentor-YR(E) relationship development and to explore dynamics in the relationship. How/either YR(E) $S$ were integrated into research group, how knowledge was transferred to the candidate, how did they resolve conflicts, etc.? The most prevalent themes in mentor-YR $(\mathrm{E})$ relationship were leadership, teamwork, collegiality, trust building, common goals, reciprocity in knowledge sharing and to motivate with praise and approval.

That I was part of a team. That I was asked what do I think and if the suggestion was a good one it was accepted. And even if it wasn't accepted, I was given feedback. [YR_F]

Providing opportunities [...] with this, a candidate can take advantages of his potentials. To give him knowledge, open the doors, to orient him correctly and provide themes of proper width. To be able to find focus candidate can follow. To be part of the research sphere, from collaboration in projects' implementation, to projects' administration. Through project administration 
they can learn a lot, and project application [...] the whole idea is expressed there. [MNT_D]

To lift you up when you're down. [YRE_D]

When you're working on something but you don't know how to go on. When he comes by and says 'try this' and you say 'aha.' [YRE_A]

[...] trust. [YR_D]

Support is very important. To open the doors for them, to warn them, to give them freedom in research - as mentors, we're not omniscient. Providing focus and to narrow the theme. [MNT_B]

There's no easy way. To cover his back - to a certain degree. [MNT_A]

\section{Obstacles in Mentor-YR(E) Relationship}

Participants reported about various obstacles in the process of mentoring. Three kinds of obstacles were identified, namely (1) programme obstacles, (2) higher education obstacles and problems with employment of young doctors of science and (3) interpersonal obstacles. We report only about the latter, as they are being connected to study aims. Among interpersonal obstacles, personal factors dominated. Participants also reported about negative attitudes toward research and clashes of interests.

Many times they want to obstruct research in companies. Do not let him be alone. [MNT_A]

When I received an invitation for business course, my director said 'What's the point, do you intent to found a company, we don't support it.' Again clash of interests. [YRE_B]

They didn't work on their $\mathrm{PhD}$ before. In the beginning, one has to fall down, to realise and reset one's mind-set that a $\mathrm{PhD}$ is not an extended version of a diploma. [MNT_E]

\section{Proposals for Improvement}

During discussions about obstacles and problems as well as about positive experience in the relationships between mentors and YR $(\mathrm{E}) \mathrm{S}$, participants provided some ideas for training improvement and for more effective mentorship. As examples below show, companybased mentors and (co-)mentors from academia should have more frequent communication; common goals should be developed regarding research project and thesis writing. 
All three mentors should have common meetings. In order to see how many different views and interests there are. You always have in your head: what do other mentors say about this? [YRE_C]

Trial period was suggested, in which mentors and/or YR(E) S could know each other better and in some cases resign from their formal role in case one or more parties find the other party as not competent or not motivated enough.

The main purpose is to teach a YR the process of doing research. He has to go through this process on his own, from research idea, through results and defending it, soft skills, presenting one's work. In economy there's nothing without these skills. [YRE_B]

We started one month earlier, voluntarily, so that at least we knew where the paper is when the printer runs out of it and where the toilets are. [YR_G]

A comprehensive evaluation of the YR training should be made on a national level, with an emphasis on relationships between all stakeholders and with cases of successful practices.

\section{Discussion}

Present research indicated that the relationship with the mentor is important for the assessment of the usefulness of the YR(E) training. The relationship with the mentor has a higher impact in the YR group. With this, hypothesis 1 was confirmed. This is in line with several other studies that suggest that constructive relationships between mentors and doctoral students lead to positive outcomes for the students, such as academic excellence and psychological wellbeing (Devos et al. 2015; Curtin, Malley, and Stewart 2014; Titus and Ballou 2014; Mainhard et al. 2009; Paglis, Stephen, and Bauer 2006).

Additionally, analysis of focus groups showed anomalies in mentorYR(E) relationship on one hand and cases of good practise on the other. These anomalies derive from different positions when entering the programme (by YR $(\mathrm{E}) \mathrm{S}$, by mentors as well as on an institutional level).

Prevailing positive characteristics of good mentors in $\mathrm{YR}(\mathrm{E})$ training, as reported by YR $(\mathrm{E}) \mathrm{S}$ and mentors were very much in line with previous research findings (Bell-Ellison and Dedrick 2008; Lechuga 2011; 2014). Primarily they sought for active support in involving the YR $(\mathrm{E}) \mathrm{S}$ into all phases of research projects and research group. 
Among soft skills, good communication skills and teamwork orientation as well as mentor's support were recognised as prevalent attributes of high quality mentors. In this way, YR(E)S are not only provided with discipline and research-specific knowledge and skills, but also develop soft skills, such as teamwork, communication, especially argumentation. With this, they gain in confidence and are able to identify with career of a researcher. While being included in projects of various end-users they also develop several employability skills, which might be useful in their future careers as the situation in the Slovenian labour market (and also in majority of other European and other OECD countries; see Müller 2014) is not bright for young doctors of science. It is advised that mentor is evaluated for above mentioned skills by YR(E) and this evaluation becomes an integral part of his future applications to the Call for mentors for YR(E)S.

Prevailing positive characteristics of promising YR $(\mathrm{E}) \mathrm{S}$ were also recognised. Some mentors discussed about cases of YR (E)S not being independent or motivated enough for the research work. In worst cases, mentors reported about YR (E)S with scarce knowledge of methodology and other research-specific skills. We can conclude that while YR $(\mathrm{E}) \mathrm{s}$ reported a lot about technical and soft skills of mentors, mentors were primarily concerned about personal characteristics and about technical skills of their mentees. It is advised that mentors evaluate personal characteristics and technical skills of YR $(\mathrm{E})$ candidates in more detail. Additional tests could be developed and applied in the selection process in order to measure candidates' personality and research skills and to minimise the costs for less fortunate selection of YR.

This study provides insights into personal dimensions of the relationships in the $\mathrm{YR}(\mathrm{E})$ training as perceived directly by participants who have been involved in the programme. The study adds to the field of mentoring in higher education in a way, that relational parties have to be aware of the tensions, and then tensions have to be interpreted and redirected in a way that contributes to more productive relationships (Goodman 2006).

In second hypothesis we proposed the relationship with the mentor is important for YR(E) knowledge transfer. Knowledge transfer was perceived as two-way integration of research sphere and endusers, mainly the economy, but also as a progress of science and interdisciplinary research. This is why knowledge transfer was directly measured with number of projects completed or in progress. As the results show, this was not sufficient measurement of knowledge transfer, for the model was not statistically significant. Thus, we 
have to conclude that second hypothesis was not confirmed by using survey data. Focus groups on the other hand showed that all three groups recognised knowledge transfer as one of prevailing motives behind YR $(\mathrm{E})$ programme. Knowledge transfer is possible in mentorYR(E) tandem where both parties share common goals and motivation.

In the future, more positive cases of relationships between mentors and YR $(\mathrm{E}) \mathrm{S}$ should be seen in public. With this, role-models of a high quality mentoring process might be recognised. As a result, more competent and self-confident professionals are expected, who will contribute to better results in science and in society at large.

\section{Research Limitations and Suggestions for Further Research}

The Slovenian $\mathrm{YR}(\mathrm{E})$ training programme is unique in the world, so literature on high quality relationship between mentors and YR $(\mathrm{E}) \mathrm{S}$ is scarce. In search of characteristics of high quality relationships between mentors and YR $(\mathrm{E}) \mathrm{S}$ we therefore made a literature overview of relationships between mentors and doctoral students in general even though differences between 'regular' doctoral students and YR (E)S might exist especially due the fact that for a YR(E) position, mostly only the best future doctoral students are selected.

Secondly, the relatively low response rate (slightly more than $14 \%$ ) has to be addressed. It is assumed this was because a long and time consuming questionnaire was used in the research. Additionally, Slovenian researchers are exposed to many surveys on a weekly basis so it is difficult to take part in all of them. From a methodological standpoint, also use of self-report measures might be problematized as it might lead to either underreporting or over-reporting of behaviour under observation.

The relationship between YR and faculty mentors has been identified as a key determinant in the process and successful completion of PhD thesis (Holley and Caldwell 2012). However, other important factors, such as programme specifics and its shortcomings, institutional support and barriers, financial support, motivation of both mentors and YR for professional development etc. have not been addressed. The methodological approach also did not allow us to make conclusions about possible differences among disciplines or individual institutions. These factors should be addressed in forthcoming research.

Since hypothesis 2 was not confirmed due to insufficient data about knowledge transfer, we conclude measurement of knowl- 
edge transfer should have been more elaborated. Different kinds of knowledge transfer should have been involved in the survey, such as teaching at the university or elsewhere, community work, other kinds of collaboration with companies (informal projects), etc. Additionally, academic mentors' task is to support the YRS and YRES in preparation of their doctoral thesis and the (economy, SR) projectbased knowledge transfer aspect is only an additional benefit. However, it should be considered to activate and empower the academic mentors on this kind knowledge transfer aspect of training in order for the programme to become more efficient.

The number of focus groups that were conducted in present research was rather small. Literature (Greenbaum 1998) advises 5-8 participants should take part in each focus group in order for answers to reiterate and to achieve a good fit with reality. On the other hand, three focus groups were conducted in our case, but answers started to overlap anyway. This shows that regardless of smaller sample size it was still possible to achieve enough diversity in answers.

According to literature (Greenbaum 1998, 181, 231) another formal criterion is that participants should not know each other in the beginning of focus groups in order to be independent. This was not achieved in two out of three focus groups in the present research, where two participants knew each other. Unfortunately limited access to participants and their limited interest to be part of the study did not allow realisation if this condition. Also not all disciplines were (equally) covered in focus groups so it is possible that some important aspects of mentor-YR relationship were not covered in the research.

Furthermore, adopted methodological approach also did not allow exploration of differences between completers and non-completers. For example, Devos et al. (2016) found that doctoral students who completed their thesis are different from non-completers in a level of anxiety and perception of moving forward with the process of thesis preparation. Furthermore, completers differentiated from noncompleters in a degree, to which they perceived their research as meaningful. In the future research, it would make sense to compare ex YR(E)S who successfully completed the programme and those who were not successful and to explore mentors' role in the process of (non-)completion of the YR(E) programme.

Studies show significant, although complex, relationships of mentoring styles and PhD students' outcomes (Devos et al. 2015). The question is how much involvement, autonomy and support should 
mentors offer in order to reach best results? So in the future, we will focus on exploring mentoring styles and their relationship on (non-) completion of postgraduate studies.

In literature review (Devos et al. 2016; Arzenšek, Košmrlj and Širca 2014; Bair and Haworth 2004) psychological dimensions of doctoral experience show new and promising direction in the study of doctoral students' persistence and attrition. By focussing on internal factors such as motivation, self-efficacy and candidate personality, we will be able to complement existing research and provide better insights about relationship between mentors and YR(E) in the future.

\section{References}

Anderson, E., and A. Shannon. 1988. 'Toward a Conceptualization of Mentoring.' Journal of Teacher Education 39 (1): 38-42.

Arzenšek, A., K. Košmrlj, and N. Trunk Širca, 2014. 'Slovenian Young Researchers' Motivation for Knowledge Transfer.' Higher Education 68:185-206.

Bair, C., and J. G. Haworth. 2004. 'Research on Doctoral Student Attrition and Retention: A Meta Synthesis.' In Higher Education: Handbook of Theory and Research, edited by J. C. Smart, 481-534. New York: Agathon.

Bell-Ellison, B. A., and R. F. Dedrick. 2008. 'What do Doctoral Students Value in their Ideal Mentor?' Research in Higher Education 49:55567.

Churchill, G. A., and D. Iacobucci. 2005. Marketing research: Methodological Foundations. 10th ed. Cincinnati, OH: South-Western Cengage Learning.

Curtin, N., J. Malley, and A. J. Stewart. 2014. 'Mentoring the Next Generation of Faculty: Supporting Academic Career Aspirations Among Doctoral Students.' Research in Higher Education 57 (6): 714-38.

Denicolo, P. 2004. 'Doctoral Supervision of Colleagues: Peeling off the Veneer of Satisfaction and Competence.' Studies in Higher Education 29 (6): 693-707.

Devos, C., N. Van der Linden, G. Boudrenghien, A. Azzi, M. Frenay, B. Galand, and O. Klein. 2015. 'Doctoral Supervision in the Light of the Three Types of Support Promoted in Self-Determination Theory.' International Journal of Doctoral Studies 10:438-64.

Devos, C., B. Boudrenghien, N. Van der Linden, A. Azzi, M. Frenay, B. Galand, and O. Klein. 2016. 'Doctoral Students' Experiences Leading to Completion or Attrition: A Matter of Sense, Progress and Distress.' European Journal of Psychology of Education 32 (1): 61-77.

Edmunds, H. 1999. The Focus Group Research Handbook. Lincolnwood, IL: NTC. 
Goodman, S. B. 2006. 'Autonomy and Guidance in Doctoral Advisement Relationships: A Dialectical Study.' The Humanistic Psychologist 34 (3): 201-22.

Greenbaum, T. L. 1998. The Handbook for Focus Groups Research. Thousand Oaks, cA: Sage.

Holley, K. A., and M. L. Caldwell. 2012. 'The Challenges of Designing and Implementing a Doctoral Student Mentoring Program.' Innovative High Education 37:243-53.

Lechuga, V. M. 2011. 'Faculty-Graduate Student Mentoring Relationships: Mentors' Perceived Roles and Responsibilities.' Higher Education 62 (10): 757-71.

2 2014. 'A Motivation Perspective on Faculty Mentoring: The Notion of "Non-Intrusive" Mentoring Practices in Science and Engineering.' Higher Education 68:909-26.

Mainhard, T., R. van der Rijst, J. van Tartwijk, and T. Wubbels 2009. 'A Model for the Supervisor-Doctoral Student Relationship.' Higher Education 58:359-73.

Morgan, D. L. 1997. Focus Groups as Qualitative Research. Thousand Oaks, cA: Sage.

Müller, R. 2014. 'Postdoctoral Life Scientists and Supervision Work in the Contemporary University: A Case Study of Changes in the Cultural Norms of Science.' Minerva 52:329-49.

Paglis, L. L., G. G. Stephen, and T. N. Bauer. 2006. 'Does Adviser Mentoring Add Value? A Longitudinal Study of Mentoring and Doctoral Student Outcomes.' Research in Higher Education 47 (4): 451-76.

Paré, A. 2011. 'Speaking of Writing: Supervisory Feedback and the Dissertation.' In Doctoral Education: Research-Based Strategies for Doctoral Students, Supervisors and Administrators, edited by L. McAlpine and C. Amundsen, 59-74. Dordrecht: Springer.

Patton, M. Q. 2002. Qualitative Evaluation and Research Methods. 3rd ed. Thousand Oaks, cA: Sage.

Seagram, B. C., J. Gould, and S. W. Pyke. 1998. 'An Investigation of Gender and Other Variables on Time to Completion of Doctoral Degrees.' Research in Higher Education 39 (3): 319-35.

Slovenian Research Agency. 2017. 'Young Researchers.' http://www.arrs .gov.si/en/mr/

Titus, S. L., and J. M. Ballou. 2014. 'Ensuring php Development of Responsible Conduct of Research Behaviors: Who's Responsible?' Science and Engineering Ethics 20 (1): 221-35.

This paper is published under the terms of the Attribution-

NonCommercial-NoDerivatives 4.o International (CC BY-NC-ND 4.0)

License (http://creativecommons.org/licenses/by-nc-nd/4.o/). 